\title{
QUALIDADE FISIOLÓGICA DE SEMENTES DE MELANCIA EM FUNÇÃO DA PRÉ- HIDRATAÇÃO E ARMAZENAMENTO
}

\author{
PINTO, Joyce de Almeida ${ }^{1}$ \\ MANHONE, Pedro Ramon² \\ VENANCIO, Luan Peroni ${ }^{3}$ \\ LOPES, José Carlos ${ }^{4}$
}

\begin{abstract}
Recebido em: 2020.01.17 Aprovado em: 2021.04.16 ISSUE DOI: 10.3738/1982.2278.3737
RESUMO: A melancia está entre as mais importantes e comercializadas olerícolas do Brasil, sendo úteis aos produtores, portanto, estudos que visam o aumento da germinação e do vigor de suas sementes. Objetivou-se neste trabalho avaliar a qualidade fisiológica de sementes de melancia cv. Crinsom sweet pré-hidratadas e armazenadas. O delineamento experimental foi o inteiramente casualizado com quatro repetições, no esquema fatorial $6 \times 4$ (seis períodos de embebição $(0,6,12,18,24$ e 30 horas) e quatro tempos de armazenamento $(0,15,30$ e 45 dias $)$ ). A qualidade das sementes foi avaliada por meio do teor de água, peso de mil sementes, primeira contagem, teste de germinação, índice de velocidade de germinação, comprimento de parte aérea e raiz principal e massa fresca e seca da parte aérea e raiz. A hidratação das sementes por 12, 18 e 24 horas e armazenamento por 15 dias favorecem a germinação, massa fresca e comprimento das plântulas, além de reduzir o número de plântulas anormais.
\end{abstract}

Palavras chave: Citrullus lanatus. Embebição. Germinação. Vigor.

\section{PHYSIOLOGICAL QUALITY OF SEEDS OF WATERMELON IN THE FUNCTION OF PRÉ-HIDRATATION AND STORAGE}

SUMMARY: Watermelon is one of the most important and commercialized vegetables in Brazil, being useful to producers, therefore, studies that aim at increasing germination and the vigor of its seeds. The objective of this study was to evaluate the physiological quality of prehydrated and stored watermelon seeds cv. Crinsom sweet. The experimental design was a completely randomized design with four replications, in the 6 x 4 factorial scheme (six soak periods $(0,6,12,18,24$ and 30 hours) and four storage times $(0,15,30$ and 45 days $))$. Seed quality was evaluated by water content, weight of one thousand seeds, first count, germination test, germination speed index, shoot length and main root, and fresh and dry mass of shoots and roots. The hydration of the seeds for 12,18 and 24 hours and storage for 15 days favor the germination, fresh mass and seedling length, in addition to reducing the number of abnormal seedlings.

Keywords: Citrullus lanatus. Soaking. Germination. Vigor.

\section{INTRODUÇÃO}

Entre as mais importantes olerícolas produzidas e comercializadas no Brasil está a melancia (Citrullus lanatus), pertencente à família das cucurbitáceas e originária do continente africano; isso se dá não somente pelas suas características nutricionais como também pelo seu valor comercial (BHERING et al., 2003).

\footnotetext{
${ }^{1}$ Doutoranda no Programa de Pós-Graduação em Ciências Florestais da Universidade Federal do Espírito Santo; ${ }^{2}$ Professor EBTT do Instituto Federal do Maranhão; ${ }^{3}$ Pesquisador líder do grupo de trabalho Manejo de altas produtividades do Centro de Excelência em Agro Exponencial (CEAGRE/IF Goiano/Rio Verde). ${ }^{4}$ Professor titular da Universidade Federal do Espírito Santo.
} 
Para um bom desenvolvimento e produção, inicialmente as plantas dependem do êxito no momento da germinação, bem como o vigor das sementes. A germinação está ligada ao processo de embebição de água pela semente, que desencadeia uma sequência de mudanças metabólicas que culminam com a protrusão da radícula, quando se refere a sementes viáveis não dormentes (LABORIAU, 1983; CARVALHO; NAKAGAWA, 2012). A absorção de água depende da espécie, da semente, variedade ou cultivar, temperatura ambiente, composição química da semente, teor de umidade inicial, natureza do tegumento e quantidade de água disponível (SOUZA et al., 2008). A embebição da maioria das sementes segue um padrão trifásico (BEWLEY; BLACK, 1994) onde na fase inicial do processo (fase I) tanto as sementes vivas quanto as sementes mortas ou dormentes, exceto por impermeabilidade do tegumento, absorvem água. Na segunda etapa (fase II) ocorre a reativação metabólica, onde as reservas são convertidas em compostos necessários para a germinação. A duração de cada etapa varia de acordo com as propriedades inerentes às sementes de cada espécie e das condições térmicas e hídricas durante a hidratação (VERTUCCI, 1989). Na terceira etapa (fase III) ocorre aumento na concentração de solutos na célula, ocorrendo à expansão do embrião e a protrusão da raiz primária, necessitando, portanto, do conhecimento da curva de embebição de cada espécie.

Como uma boa alternativa para proporcionar maior germinação das sementes e mais rápida e uniforme emergência de plântulas no campo, tem sido estudado o uso de tratamentos pré-semeadura. Heydecker et al. (1975) propôs o tratamento de pré-condicionamento, técnica que envolve o controle da hidratação das sementes, em tempo suficiente para permitir que os processos preparatórios essenciais à germinação ocorram sem que haja protrusão da radícula. Em seguida, as sementes podem ou não ser desidratadas. A pré-hidratação permite o desdobramento de reservas e a síntese de metabólitos necessários à germinação, fazendo com que ocorra uma germinação mais rápida das sementes, diminuindo o seu tempo de exposição às condições desfavoráveis, tais como ataques por microrganismos e deficiência hídrica, dentre outras (MARCOS-FILHO, 2015). Neste sentido, as Regras para análise de sementes (RAS), sugerem um período de seis horas de imersão das sementes de melancia em água, visando o aumento no percentual de germinação (BRASIL, 2009), o que indica a influência positiva deste tipo de tratamento para esta espécie.

Outro fator a ser considerado é o armazenamento das sementes, que é iniciado no momento em que a maturidade fisiológica é atingida no campo, sendo considerado como ponto de maior qualidade das mesmas (HARRINGTON, 1971). As condições ambientais e de manejo Nucleus, v.18, n.1, abr. 2021 
das sementes influenciam diretamente a sua qualidade fisiológica, pois podem acelerar ou retardar o processo de deterioração.

Quando se trata da qualidade, a análise de sementes também é um aspecto importante, pois são testes que fornecem uma estimativa do desempenho das mesmas em campo ou no armazenamento. Diversos testes podem ser utilizados para avaliação do potencial fisiológico das sementes, como por exemplo, o teste de primeira contagem de germinação, índice de velocidade de germinação, comprimento, massa seca e fresca de plântulas normais e anormais, teste de condutividade elétrica, teste de envelhecimento acelerado e teste de frio. Estes testes, que avaliam o vigor das sementes, são indicados para identificar diferenças entre lotes e diferentes tratamentos (MARCOS-FILHO, 2015). Tais testes foram utilizados em diversos estudos para analisar o vigor de sementes de cucurbitáceas, como os realizados por Manhone et al. (2015) e Miranda et al. (2020) ao estudar sementes de melão (Cucumis melo L.), Sales et al. (2015) em sementes de abóbora tipo Moranga (Cucurbita máxima) e Araújo et al. (2020) ao trabalhar com estresse salino e diferentes temperaturas na germinação de sementes de luffa (Luffa operculata L. Cogn.).

Esse estudo teve o objetivo de avaliar a influência da pré-hidratação e armazenamento de sementes de melancia em sua qualidade fisiológica.

\section{MATERIAL E MÉTODO}

O experimento foi conduzido no Laboratório de Análise de Sementes do Centro de Ciências Agrárias e Engenharias da Universidade Federal do Espírito Santo (CCAE-UFES), sendo analisadas sementes de melancia cultivar Crinsom sweet de um lote comercial.

A curva de embebição foi feita através da porcentagem de água nas sementes. Esta foi obtida embebendo-se quatro repetições, contendo 25 sementes cada, em água destilada, e nos períodos (pontos) de embebição as sementes foram secas em papel absorvente e pesadas em balança de precisão para assim serem calculadas as porcentagens de água absorvida ao longo do tempo de embebição, em relação à umidade inicial das sementes obtida através da secagem pelo método de estufa a $105 \pm 3{ }^{\circ} \mathrm{C}$ por 24 horas, de acordo com as Regras para Análise de Sementes (BRASIL, 2009). As leituras foram feitas às 0, 6, 12, 18, 24 e 30 horas de embebição, sendo estes os pontos da curva de embebição das sementes.

O tratamento das sementes foi constituído de seis diferentes períodos de embebição $(0,6$, 12, 18, 24 e 30 horas), onde as sementes foram dispostas em bandejas e imersas (um terço da semente) em água destilada, à temperatura de $30{ }^{\circ} \mathrm{C}$ em incubadora tipo Biochemical Oxygen Demand (B.O.D.). Depois de cada período de embebição, foram retiradas quatro repetições de 25 sementes, secas em papel absorvente para remoção do excesso de água na parte externa da 
semente, acondicionadas em sacos plásticos e armazenadas em câmara fria a $25{ }^{\circ} \mathrm{C}$ e aproximadamente $50 \%$ de umidade relativa do ar, para serem analisadas em cada um dos tempos de armazenamento $(0,15,30$ e 45 dias), após os quais as sementes foram avaliadas pelos testes descritos a seguir.

Para definição da qualidade fisiológica das sementes, após os tratamentos foram avaliados os seguintes parâmetros ou testes:

Teor de água (TA) - Determinado utilizando-se duas amostras com subamostras de 10 sementes para cada tratamento, pelo método de estufa regulada a $105 \pm 3{ }^{\circ} \mathrm{C}$ por 24 horas, de acordo com as Regras para Análise de Sementes (BRASIL, 2009).

Peso de mil sementes (PMS) - Utilizaram-se oito subamostras de 100 sementes para cada tratamento, a partir das quais estimou-se o peso de mil sementes, conforme metodologia descrita por Brasil (2009).

Primeira contagem de germinação (PC) - Determinada juntamente com o teste de germinação, sendo registrada a porcentagem de sementes germinadas, uma vez que nenhum dos tratamentos apresentou plântulas normais no quinto dia após a instalação do ensaio, adaptada de acordo com as Regras de Análises de Sementes (BRASIL, 2009).

Teste de germinação (G) - Utilizaram-se 100 sementes por tratamento, subdivididas em quatro repetições de 25 sementes distribuídas em placas de Petri umedecidas com $5 \mathrm{~mL}$ de água destilada, mantidas em câmaras de germinação tipo BOD a $25^{\circ} \mathrm{C}$, com fotoperíodo de oito horas de luz por 16 horas de escuro, conforme Brasil (2009). A avaliação foi realizada no décimo quarto dia após a semeadura, considerando-se germinadas as sementes que emitiram raiz primária com aproximadamente 2 milímetros de comprimento. Os resultados são expressos de acordo com a fórmula citada por Labouriau e Valadares (1976):

- Porcentagem de germinação: $G=(N / A) .100$

Onde: $\mathrm{G}=$ porcentagem de germinação; $\mathrm{N}=$ número de sementes germinadas; $\mathrm{A}=$ número total de sementes colocadas para germinar.

Índice de velocidade de germinação (IVG) - Calculado pelo somatório do número de sementes germinadas a cada dia, dividido pelo número de dias decorridos entre a semeadura e a germinação, de acordo com a fórmula definida por Maguire (1962).

- Índice de velocidade de germinação: $I V G=\sum(n i / t i)$

Onde: ni = número de sementes germinadas a cada dia; $\mathrm{ti}$ = número de dias decorridos após a semeadura. 
Comprimento de parte aérea (CPA) e da raiz principal (CR) - As plântulas normais foram medidas com auxílio de papel milimetrado, 14 dias após a semeadura, sendo expressas em centímetro por planta $\left(\mathrm{cm} \cdot \mathrm{pl}^{-1}\right)$.

Massa fresca da parte aérea (MFPA) e da raiz (MFR) - Obtida a partir da pesagem, em balança de precisão, da massa fresca da parte aérea e da raiz das plântulas normais, em miligramas, sendo expressa em miligramas por planta $\left(\mathrm{mg} \cdot \mathrm{pl}^{-1}\right)$.

Massa seca da parte aérea (MSPA) e da raiz (MSR) - Obtida através da pesagem da massa seca da parte aérea e da raiz das plântulas normais após secagem em estufa à $80{ }^{\circ} \mathrm{C}$ até obtenção de peso constante (em torno de 72 horas), também expressa em mg.pl ${ }^{-1}$.

O delineamento experimental utilizado foi inteiramente casualizado com 24 tratamentos e quatro repetições, totalizando 96 parcelas. Cada parcela foi constituída de 25 sementes de melancia, segundo metodologia descrita por Brasil (2009). Os tratamentos corresponderam a seis diferentes tempos de embebição $(0,6,12,18,24$ e 30 horas) e quatro diferentes períodos de armazenamento $(0,15,30$ e 45 dias).

Os dados obtidos foram submetidos à análise de variância $(\mathrm{p} \leq 0,05)$ utilizando-se $\mathrm{o}$ Software SAEG 9.0 (2005), e quando significativas, as médias foram comparados pelo teste de Tukey no nível de $5 \%$ de probabilidade.

\section{RESULTADO E DISCUSSÃO}

A curva de embebição foi obtida, de acordo com a Figura 1, confirmando o padrão trifásico descrito por Bewley e Black (1994), apresentando altas taxas de absorção de água nas primeiras 6 horas de embebição, seguidas por uma fase de estabilização do processo. Essa absorção desencadeia todo o processo germinativo de sementes vivas.

Figura 1 - Curva de embebição de sementes de melancia (Citrullus lanatus cv. Crinsom sweet).

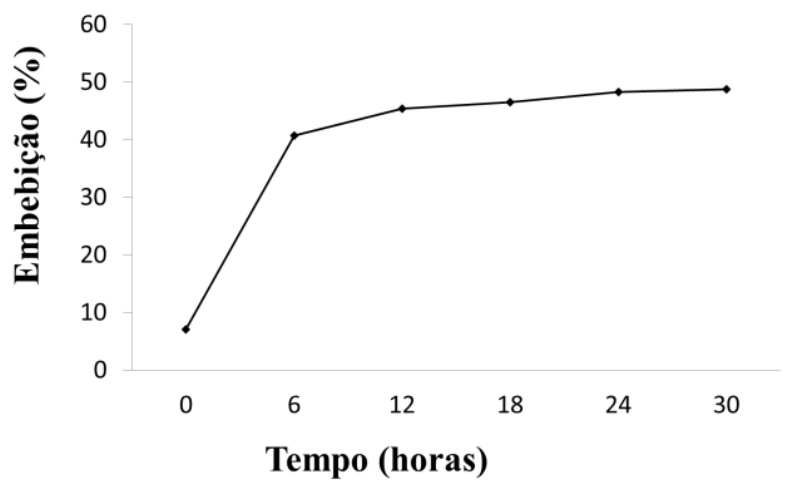

Fonte: Elaborado pelo Autor. 
As sementes de melancia são consideradas ortodoxas, logo, mesmo com baixos teores de umidade, ainda mantém sua viabilidade. A umidade inicial das sementes sem tratamento foi de $5 \%$, no entanto, variou de acordo com o tempo de embebição e o período de armazenamento. A uniformização da umidade no início dos testes é necessária para maior padronização das avaliações. No momento da embebição, o teor de água das sementes chegou a $51 \%$ (embebição por 24 horas), mas em seguida foram secas por meia hora em temperatura ambiente sobre papel absorvente para redução do teor de água das mesmas. Após o armazenamento, a umidade das sementes manteve-se entre 8 e $21 \%$ para todos os períodos de embebição, conforme mostrado na Figura 2.

Figura 2 - Umidade (\%) de sementes de melancia (Citrullus lanatus cv. Crinsom sweet) submetidas a diferentes períodos de embebição e armazenamento.

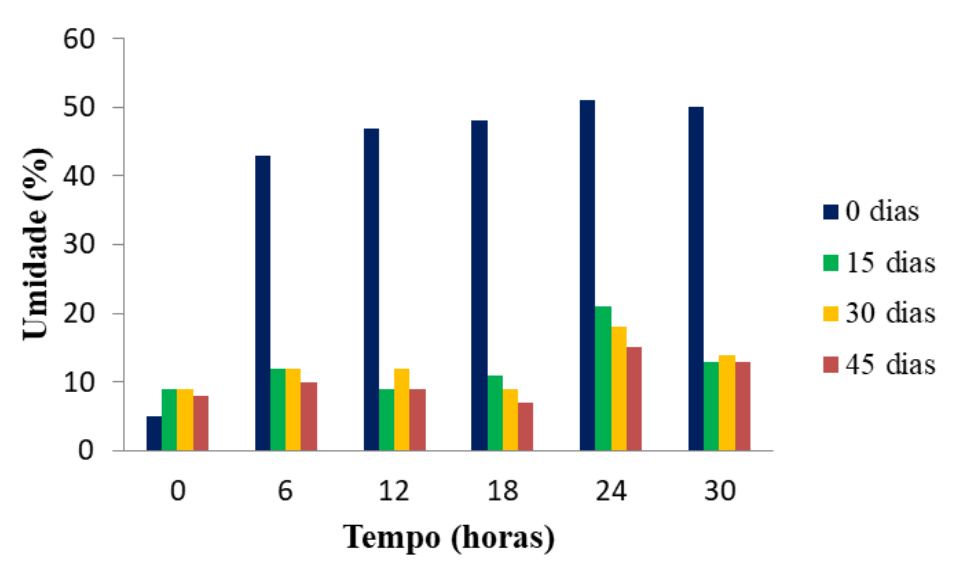

Fonte: Elaborado pelo Autor.

O peso de mil sementes (PMS) foi calculado de acordo com as recomendações, e o resultado foi igual a 42,06g, com coeficiente de variação igual a 2,3\%, sendo considerado aceitável para as sementes da espécie em estudo.

Verificou-se que as sementes submetidas aos tratamentos de 6, 12, 18 e 30 horas e armazenados por 45 dias apresentaram os maiores valores para o teste de primeira contagem de germinação (PC), chegando a 92 e 94\% de germinação ainda no quinto dia após a semeadura, conforme observado na Figura 3A. De acordo com Almeida et al (2010), o teste de primeira contagem pode ser indicado para avaliação do potencial fisiológico de sementes de melancia em laboratório, pela simplicidade e eficiência. Mas, mesmo que a primeira contagem de germinação possa ser considerada um indicativo de vigor, sabe-se que a redução da velocidade de germinação não está entre os primeiros eventos do processo de deterioração de sementes (MARCOS-FILHO, 2015).

Nucleus, v.18, n.1, abr. 2021 
Figura 3 - A) Primeira contagem (PC), B) Índice de velocidade de germinação (IVG), C) Germinação (G), D) Porcentagem de Plântulas anormais (PLA), E) Massa fresca da parte aérea (MFPA), F) Massa fresca da raiz (MFR), G) Massa seca da parte aérea (MSPA), H) Massa seca da raiz (MSR), I) Comprimento da parte aérea (CPA) e J) Comprimento da raiz (CR) de sementes de melancia (Citrullus lanatus) préhidratadas e armazenadas.

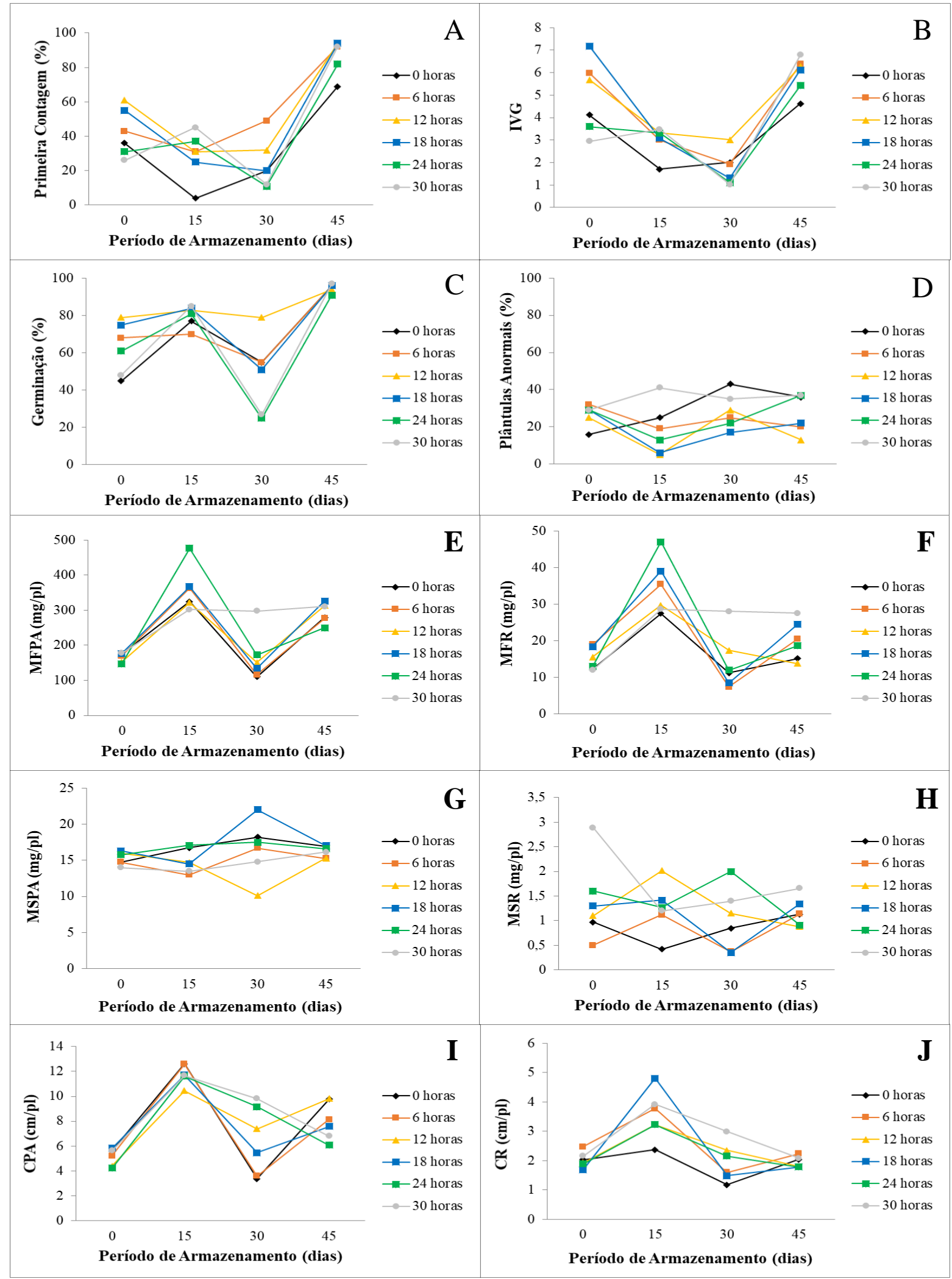

Fonte: Elaborado pelo Autor. 
O índice de velocidade de germinação evidenciou resultados similares (Tabela 1) a primeira contagem (Tabela 2) e o teste de germinação (Tabela 3) quanto ao período de armazenamento, porém, as sementes recém-tratadas (0 dias de armazenamento) e armazenadas por 45 dias mostraram altos índices de velocidade de emergência, sendo o maior valor verificado para a embebição por 18 horas, sem armazenamento $(7,18)$. Como mencionado acima, a germinação apresentou os maiores valores para as sementes armazenadas por 45 dias, independente do período de pré-hidratação, com resultados similares aos encontrados para os tratamentos de 12, 18, 24 e 30 horas, armazenados por 15 dias. Esse maior potencial fisiológico das sementes pré-hidratadas é similar ao encontrado por Nunes, Pinheiro e Dutra (2019), em sementes de feijão-caupi, onde verificaram que, ao serem pré-hidratadas, as sementes apresentam nível maior de organização das membranas celulares, quando comparadas as não hidratadas.

Tabela 1 - Índice de velocidade de germinação (IVG) de sementes de melancia (Citrullus lanatus) pré-hidratadas e armazenadas.

\begin{tabular}{ccccccc}
\hline \multirow{2}{*}{ Armazenamento (dias) } & \multicolumn{7}{c}{ Embebição (horas) } \\
\cline { 2 - 7 } & 0 & 6 & 12 & 18 & 24 & 30 \\
\hline 0 & $4,12 \mathrm{Abc}$ & $5,98 \mathrm{Aab}$ & $5,69 \mathrm{Aab}$ & $7,18 \mathrm{Aa}$ & $3,60 \mathrm{Bbc}$ & $2,94 \mathrm{Bc}$ \\
15 & $1,70 \mathrm{Ba}$ & $3,00 \mathrm{Ba}$ & $3,31 \mathrm{Ba}$ & $3,08 \mathrm{Ba}$ & $3,32 \mathrm{Ba}$ & $3,48 \mathrm{Ba}$ \\
30 & $2,00 \mathrm{Bab}$ & $1,93 \mathrm{Bab}$ & $3,01 \mathrm{Ba}$ & $1,31 \mathrm{Cc}$ & $1,11 \mathrm{Cb}$ & $1,02 \mathrm{Cb}$ \\
45 & $4,62 \mathrm{Aa}$ & $6,38 \mathrm{Aa}$ & $6,27 \mathrm{Aa}$ & $6,12 \mathrm{Aa}$ & $5,42 \mathrm{Aa}$ & $6,79 \mathrm{Aa}$ \\
\hline
\end{tabular}

As médias seguidas por uma mesma letra maiúscula nas colunas e minúscula nas linhas não diferem entre si em nível de 5\% de probabilidade pelo teste de Tukey.

Tabela 2 - Teste de primeira contagem (PC) de sementes de melancia (Citrullus lanatus) préhidratadas e armazenadas.

\begin{tabular}{ccccccc}
\hline \multirow{2}{*}{ Armazenamento (dias) } & \multicolumn{7}{c}{ Embebição (horas) } \\
\cline { 2 - 7 } & 0 & 6 & 12 & 18 & 24 & 30 \\
\hline 0 & $36 \mathrm{Bbc}$ & $43 \mathrm{BCabc}$ & $61 \mathrm{Ba}$ & $55 \mathrm{Bab}$ & $31 \mathrm{Bc}$ & $26 \mathrm{Cc}$ \\
15 & $4 \mathrm{Cb}$ & $31 \mathrm{Ca}$ & $31 \mathrm{Ca}$ & $25 \mathrm{Cab}$ & $37 \mathrm{Ba}$ & $45 \mathrm{Ba}$ \\
30 & $20 \mathrm{Bb}$ & $49 \mathrm{Ba}$ & $32 \mathrm{Cab}$ & $20 \mathrm{Cb}$ & $11 \mathrm{Cb}$ & $12 \mathrm{Cb}$ \\
45 & $69 \mathrm{Ab}$ & $92 \mathrm{Aa}$ & $94 \mathrm{Aa}$ & $94 \mathrm{Aa}$ & $82 \mathrm{Aab}$ & $92 \mathrm{Aa}$ \\
\hline
\end{tabular}

As médias seguidas por uma mesma letra maiúscula nas colunas e minúscula nas linhas não diferem entre si em nível de 5\% de probabilidade pelo teste de Tukey. 
Tabela 3 - Porcentagem de germinação $(\mathrm{G})$ de sementes de melancia (Citrullus lanatus cv. Crinsom sweet) pré-hidratadas e armazenadas.

\begin{tabular}{ccccccc}
\hline \multirow{2}{*}{ Armazenamento (dias) } & \multicolumn{7}{c}{ Embebição (horas) } \\
\cline { 2 - 7 } & 0 & 6 & 12 & 18 & 24 & 30 \\
\hline 0 & $45 \mathrm{Cb}$ & $68 \mathrm{Bab}$ & $79 \mathrm{Ba}$ & $75 \mathrm{Bab}$ & $61 \mathrm{Bab}$ & $48 \mathrm{Bb}$ \\
15 & $77 \mathrm{Ba}$ & $70 \mathrm{Ba}$ & $83 \mathrm{ABa}$ & $84 \mathrm{ABa}$ & $81 \mathrm{ABa}$ & $85 \mathrm{Aa}$ \\
30 & $55 \mathrm{BCab}$ & $55 \mathrm{Bab}$ & $79 \mathrm{Ba}$ & $51 \mathrm{Cbc}$ & $25 \mathrm{Cc}$ & $35 \mathrm{Bbc}$ \\
45 & $96 \mathrm{Aa}$ & $96 \mathrm{Aa}$ & $94 \mathrm{Aa}$ & $96 \mathrm{Aa}$ & $91 \mathrm{Aa}$ & $97 \mathrm{Aa}$ \\
\hline
\end{tabular}

As médias seguidas por uma mesma letra maiúscula nas colunas e minúscula nas linhas não diferem entre si em nível de 5\% de probabilidade pelo teste de Tukey.

Apesar dos resultados satisfatórios de primeira contagem, germinação e índice de velocidade de germinação, o número de plântulas anormais (PLA) aumentou significativamente após o armazenamento por 30 e 45 dias (Figura 3D). As menores porcentagens de plântulas anormais foram encontradas nas sementes embebidas por 6, 12, 18 e 24 horas, armazenadas por 15 dias. A porcentagem de plântulas anormais nas sementes que não foram embebidas aumentou ao longo do período de armazenamento, com uma pequena queda aos 45 dias. Além disso, as sementes inicialmente armazenadas apresentaram altas porcentagens de PLA para todos os tratamentos com embebição, conforme resultados apresentados na Tabela 4. E, a embebição por 30 horas resultou em altas porcentagens de plântulas anormais para todos os períodos de armazenamento.

Tabela 4 - Porcentagem de plântulas anormais de sementes de melancia (Citrullus lanatus) préhidratadas e armazenadas.

\begin{tabular}{ccccccc}
\hline \multirow{2}{*}{ Armazenamento (dias) } & \multicolumn{7}{c}{ Embebição (horas) } \\
\cline { 2 - 7 } & 0 & 6 & 12 & 18 & 24 & 30 \\
\hline 0 & $16 \mathrm{Ba}$ & $32 \mathrm{Aa}$ & $25 \mathrm{ABa}$ & $29 \mathrm{Aa}$ & $29 \mathrm{ABa}$ & $29 \mathrm{Aa}$ \\
15 & $25 \mathrm{ABab}$ & $19 \mathrm{Aab}$ & $5 \mathrm{Bb}$ & $6 \mathrm{Bb}$ & $13 \mathrm{Bb}$ & $41 \mathrm{Aa}$ \\
30 & $43 \mathrm{Aa}$ & $25 \mathrm{Aa}$ & $29 \mathrm{Aa}$ & $17 \mathrm{ABa}$ & $22 \mathrm{ABa}$ & $35 \mathrm{Aa}$ \\
45 & $36 \mathrm{ABa}$ & $20 \mathrm{Aa}$ & $13 \mathrm{ABa}$ & $22 \mathrm{ABa}$ & $37 \mathrm{Aa}$ & $37 \mathrm{Aa}$ \\
\hline
\end{tabular}

As médias seguidas por uma mesma letra maiúscula nas colunas e minúscula nas linhas não diferem entre si em nível de 5\% de probabilidade pelo teste de Tukey.

A massa fresca da parte aérea (MFPA) apresentou os melhores resultados para as sementes armazenadas por 15 dias, quaisquer que tenha sido o tempo de embebição (Figura 3E). Já a massa seca da parte aérea teve melhor resultado $\left(22 \mathrm{mg} \cdot \mathrm{pl}^{-1}\right)$ nas sementes embebidas por 18 horas, e armazenadas por 30 dias (Figura 3G). Para a massa fresca da raiz (MFR), as sementes armazenadas por 15 dias embebidas por 18 e 24 horas apresentaram resultados satisfatórios, como mostra a Figura 3F, sendo as massas iguais a 39,12 e 47,05 mg.pl ${ }^{-1}$, respectivamente; já 
para a massa seca da raiz (MSR) o maior valor foi encontrado na embebição por 30 horas sem armazenamento, com valor igual a 2,89 mg.pl ${ }^{-1}$ (Figura 3H).

Os parâmetros comprimento de parte aérea e raiz (CPA e CR) mostraram resultados significativos para todos os tratamentos armazenados por 15 dias. O comprimento da parte aérea mostrou valores médios de até $12,61 \mathrm{~cm} \cdot \mathrm{pl}^{-1}$ para o tratamento sem embebição armazenado por 15 dias (Figura 3I). E o tratamento com embebição por 18 horas e armazenado por 15 dias apresentou média de 4,81 cm.pl ${ }^{-1}$ para CR (Figura 3J). O tratamento pré-hidratado e armazenado por 45 dias apresentou plantas estioladas.

O processo de pré-embebição mostrou-se eficiente para a germinação e vigor das sementes de melancia cv. Crinsom sweet. Sobretudo as sementes embebidas por 6, 12, 18 e 24 horas, armazenadas por 15 dias mostraram resultados satisfatórios para os parâmetros avaliados, além de apresentar baixos percentuais de plântulas anormais (Figura 3D). Os resultados corroboram com Moraes et al. (2007), que verificaram que a imersão em água contribui de forma significativa para maximizar o processo de germinação de sementes de melancia de cavalo (Citrilus lanatus cv. Citroides); e ainda com os resultados encontrados por Manhone et al. (2015) que afirmam que o processo de embebição aumenta o potencial fisiológico das sementes de melão (Cucumis melo L.).

O armazenamento das sementes pré-hidratadas por maiores períodos de tempo causa perdas na qualidade fisiológica das sementes, observado principalmente pelo elevado número de plântulas anormais após 30 dias.

\section{CONCLUSÃO}

A pré-embebição de sementes de melancia cv. Crinsom sweet em água é eficiente para aumentar o potencial fisiológico das mesmas.

O armazenamento por 15 dias de sementes de melancia embebidas por 12, 18 e 24 horas, aumenta a germinação, massa fresca e comprimento das plântulas, além de reduzir o número de plântulas anormais.

A pré-embebição por 30 horas ocasiona aumento na porcentagem de plântulas anormais e estiolamento das mesmas para todos os períodos de armazenamento. 


\section{REFERÊNCIAS}

ALMEIDA, A.S.; PINTO, J.F.; DEUNER, C.; VILLELA, F.A. Avaliação do potencial fisiológico de sementes de melancia. Revista da FZVA. Uruguaiana, v.17, p.68-77, 2010.

ARAÚJO, P.C.; MELO, P.A.F.R.M.; ALVES, E.U.; ANJOS NETO, A.P.; ARAUJO NETO, A.C.; ARAÚJO, J.R.G.; MONDEGO, J.M.; SILVA, A.P.G.; SILVA, J.N.; MEDEIROS, M.L.S. Effects of saline stress and temperature on germination and seed vigor of Luffa operculata L. Cogn. Australian Journal of Crop Science, v.14, n.11, p.1779-1785, 2020.

BEWLLEY, J.D.; BLACK, M. Seeds: physiology of development and germination. $2^{\mathrm{a}}$ ed. New York: Plenum Press. 1994. 445p.

BHERING, M.C.; DIAS, D.C.F.S.; BARROS, D.I; DIAS, L.A.S.; TOKUHISA, D. Avaliação do vigor de sementes de melancia (Citrullus iunatus $\mathrm{Schrad}$ ) pelo teste de envelhecimento acelerado. Revista Brasileira de Sementes, v.25, p.1-6, 2003.

BIAS, A.L.F.; TILLMANN, M.A.A.; VILLELA, F.A.; ZIMMER, G.J. Métodos para avaliação da qualidade fisiológica de sementes de feijão vigna. Scientia Agrícola, v.56, 1999.

BRACCINI, A.L.; REIS, M.S.; SEDIYAMA, C.S.; SCAPIM, C.A.; BRACCINI, M.C.L. Avaliação da qualidade fisiológica de sementes de soja, após o processo de hidrataçãodesidratação e envelhecimento acelerado. Pesquisa Agropecuária Brasileira, v.34, p.10531066, 1999.

BRASIL, Ministério da Agricultura e Reforma Agrária. Regras para análise de sementes. Brasília. 2009. 365p.

CARVALHO, N.M.; NAKAGAWA, J. Sementes: ciência, tecnologia e produção. 5a ed. Jaboticabal: FUNEP. 2012. 590p.

HARRINGTON, J. Drying, storage and packaging: present status and future needs. In: Short Course for Seedsmen, Mississippi State . Proceedings... Mississippi State, v.14, p133-139, 1971.

HEYDECKER, W.; HIGGINS, J.; TURNER, I.J. Invigoration of seeds? Seed Science and Technology, v.3, p.881-888, 1975.

LABORIAU, L.G.A. Germinação das sementes. Washington: Secretaria Geral da Organização dos Estados Americanos. 1983. 171p.

LABOURIAU, L.G.; VALADARES, M.E.B. On the germination of seeds Calotropis procera (Ait.) Ait.f. Anais da Academia Brasileira de Ciências, Rio de Janeiro, v.48, p.263-284, 1976.

MAGUIRE, J.D. Speed of germination aid in selection and evaluation of seedling emergence and vigor. Crop Science, v.2, p.176-177, 1962.

MANHONE, P.R.; LOPES, J.C.; ALMEIDA, J.; VENÂNCIO, L.P.; FREITAS, A.R. Caracterização fisiológica de sementes de melão durante o armazenamento. Magistra, v.2: p.227-236, 2015. Disponível em: 
<https://magistraonline.ufrb.edu.br/index.php/magistra/article/view/382 >. Acesso em: 03 jan. 2019.

MARCOS-FILHO, J. Fisiologia de sementes de plantas cultivadas. Londrina: ABRATES. 2015. 660p.

MIRANDA, J.S.; NASCIMENTO, A.R.; DIDOLANVI, O.D.; MENEZES, A.C.P.; SANTOS, E.N. Qualidade fisiológica de sementes de melão (Cucumis melo L.) submetidas ao estresse salino. Revista Ouricuri, Juazeiro - BA, v.10, n.2, p.21-34, jul./dez., 2020.

MORAES, J.P.S.; ANGELIM, A.E.S.; SILVA, J.A.B. Monitoramento da germinação e crescimento vegetativo em plantas de Melancia de Cavalo (Citrilus lanatus cv. Citroides), encontradas no bioma Caatinga - região do Vale do São Francisco. Revista Brasileira de Biociências, v.5, p.1068-1070, 2007.

NUNES, L.R.L; PINHEIRO, P.R.; DUTRA, A.S. Potencial fisiológico de sementes de feijãocaupi submetidas à pré-hidratação. Revista de Agricultura Neotropical, Cassilândia-MS, v.6, n.1, p.54-59, 2019. Disponível em:

<https://periodicosonline.uems.br/index.php/agrineo/article/view/2646/2752>. Acesso em: 08 jan. 2019.

SAEG 9.0. Sistema para Análises Estatísticas-SAEG. Viçosa: Fundação Arthur Bernardes. Versão 9.0. 2005. CD ROM.

SALES, M.A.L; MOREIRA, F.J.C.; RIBEIRO, A.A.; MONTEIRO, R.N.F.; SALES, F.A.L. Potencial das sementes de abóbora submetidas a diferentes períodos de embebição. Brazilian Journal of Biosystems Engineering, v.9, n.4, p.289-297, 2015.

SILVA, K.R.G.; VILLELA, F.A. Pré-hidratação e avaliação do potencial fisiológico de sementes de soja. Revista Brasileira de Sementes, v.33, p.331-345, 2011.

SOUZA et al. Curva de absorção de água em sementes de mamona. In: Congresso Brasileiro de Mamona, 3, Salvador. Resumos [...] Salvador: SEAGRI: Embrapa Algodão. 2008. 36p.

VERTUCCI, C.W. The kinetics of seed imbibition: controlling factors and relevance to seedling vigor. In: Symposium Sponsored by Divison C-4 and C-2 of the Crop Science Society, Atlanta. Proceedings [...] Madion: Crop Science Society, p.93-115, 1989. (Special Publication, 14). 